\title{
Professional Learning Community and College English Teachers' Professional Development
}

\author{
Ying Zhao \\ Shandong University of Finance and Economics, Jinan, China
}

\begin{abstract}
This paper discusses the present problems in college English teachers' professional development from an educational, sociological and management viewpoints. It highlights the necessity of introducing professional learning community (PLC) into teachers' professional development and gives some suggestions at the same time. The main purpose is to promote teachers' collaborative development mode to replace the isolating and competitive one, which puts barriers to college English teachers' professional development.
\end{abstract}

Index Terms — college English teacher, teachers' professional development, professional learning community

\section{INTRODUCTION}

Since China's ELT (English Language Teaching) reform in higher education began in 2004, college English teachers' professional development has been given greater attention, as teachers' capability is the crucial factor in deciding the success of the reform.

Generally speaking, up to now most studies on college English teachers' professional development are focused on the personal dimension from a psychological or cognitive approach, such as the emphasis on individual teacher's reflective learning and reflective inquiry. The social elements like the relationship between teachers' working context and teachers' professional development are largely neglected. This paper, therefore is intended to study college English teachers' professional development from an educational, sociological and management viewpoints by introducing the concept of professional learning community (PLC) into the research.

\section{LITERATURE REVIEW}

A. Professional Learning Community (PLC)

In the last twenty years, in western countries lots of educational reformers and researchers strongly advocate developing schools as professional learning community as a systematic and effective way to improve teachers' quality. Up to now there is no universal definition of a PLC, but educational researchers unanimously agree on a view that a PLC exists in a school where a group of teachers collaboratively and critically exchange their instructional practices in an ongoing, reflective, inclusive, learning-oriented and growth-promoting way to support innovation and knowledge sharing (Mitchell\&Sackney, 2000). The concept of professional learning is often associated with professional development by many researchers, (Louis, Mark\&Kruse, 1996, Hord, 1997) who proposed five dimensions of PLC which include supportive and shared leadership, shared values and vision, collective learning and application, supportive conditions, and shared personal practice.

1. Supportive and shared leadership

In a PLC, a collaborative effort involving all members is required, as principals alone cannot produce the large-scale improvement, so many schools are adopting a distributed leadership approach to address this issue. (Camburn, et al., 2003; Neuman \& Simmons, 2000). Lambert (1998) views leadership as an organizational property which is opposed to a behavioral trait that is found within certain individuals. Thus a principal is responsible not only for building his or her own capacity, but also that of teachers and supporting the professional development of their staff. So teachers with content area expertise are encouraged to take on leadership roles in their areas of strength and beyond their classroom duties. (Camburn, et al., 2003; Crowther, Kaagan, Ferguson, \&Hann, 2002; Katzenmeryer\&Moller, 2001). They are usually called model teachers. Model teachers can act as curricular leaders, guiding staff development, sharing successful practices and serving as teaching supervisors, club advisors and mentors to students etc.. Administrators who support teacher leadership also have learned that when they give out some of their authority to teachers they can unlock the creative powers of teachers and get innovative solutions to problems. (Barth, 2001, p.49)

2. Shared values and vision

Members of a PLA have shared values and vision. A spirit of mutual trust and caring exists among teachers. They work interdependently in collaborative teams in an effort to achieve the common goal that is for the improvement of students' learning. They view their peers as resources and recognize the value they contribute as well. Every one in the community buys into the shared vision, understands the goals and agrees on the actions to be taken. Once the shared values and vision are established, teachers are no longer just responsible for what goes on within the four walls of their classroom, but the whole school at large. Students are no longer taken as my students, but rather our students. 
3. Collective learning and application

"Collective learning" or "team learning" is defined by Senge (1994, p.42) as the process of learning how to learn collectively. For most teachers, it is unfamiliar because teachers have the long tradition of working in self-contained classrooms isolated from peer interaction during the workday. Team learning unifies teachers toward a shared vision and coherence. In a PLA teachers collaborate in teaching skill and matters which are connected with students. Collegial behavior includes collegial discussion of teaching skills, sharing teaching resources, or observing one another's class. As Fullan (2005) points out, "It is not just workshops and professional development for all. It is the daily habit of working together." Lambert (2003, p.44) also advocates for team learning as "it is mutual and interactive, thereby investing in the growth of all participants"

4. Supportive conditions

Professional learning community (PLA) provides a favorable environment for teachers study by nourishing a cooperative and supportive school culture. Being involved in this network offers teachers the opportunity to see themselves as part of a broader profession, where teachers are supported in learning new knowledge and skills and are encouraged to help others to learn, they are provided with the needed assistance, guidance and coaching. In the positive environment, teachers experience general satisfaction.

5. Shared personal practice

Teacher professional learning community is a community of teachers and teaching practice, in which teachers can improve their work by learning "tacit knowledge" of their colleagues which are called by Wenger (1998). Fullan (1999, p.15) also mentioned the importance of sharing tacit knowledge, saying "the secret to success of living companies, complex adaptive system, learning community or whatever terms we use, is that they consist of intricate, embedded interaction inside and outside the organization which converts tacit knowledge to explicit knowledge on an ongoing basis". In the case of teacher professional learning community, teachers can share tacit knowledge through collegiate and collaborative activities in their daily work such as collegial conversations, coaching sessions, shared decision-making, as well as other interactive events.

\section{B. Teacher Professional Development}

In the educational reform of the new millennium around the world, teachers are regarded as both the objects and subjects of change, thus making teachers' professional development become an ever-growing and challenging area that has got great focus in the past years. On studying the recent educational literature, it can be generally concluded that teachers' professional development includes: (Guskey, 2000) "opportunities for educators to discuss, think about, try out, and hone new practices in an environment that values inquiry"; formal experiences such as attending professional meetings, collegiate discussion and cooperation in workshops, guiding novice teachers etc. , the informal experiences like reading professional books and magazines, watching teaching videos etc. (Ganser, 2000).

To summarize, the new tendency of teacher professional development is the traditional "in-service training" being replaced by a long-term process which emphasizes regular systematically-planned opportunities and activities to promote the growth and development of their profession. It is also conceived of as a collaborative process. This new path moves educators away from a view of teaching as a solitary activity, owned personally by each teacher. The view of teaching profession can be regarded as the activity with open access to cooperative observations, learning, and improving their teaching capability. It makes common teachers realize and accept the notion that they are responsible for honing not only their own practice, but also the shared activities of their colleagues. For the newly explored path, however, teachers will need to open their classroom doors and studying their practices as a professional responsibility, rather than only evaluating each other. (Hiebert, Gallimore, and Stigler, 2003)

\section{The Introduction of Professional Learning Community to College English Teachers' Professional} DEVELOPMENT

\section{A. The Necessity of Introducing Professional Learning Community into College English Teachers' Professional Development}

Although cooperation is regarded as a powerful resource for sharing knowledge among teachers and advancing professional development, engaging all teachers in professional cooperation still remains one of the greatest challenges for teacher-leaders. (Liberman \& Miller, 2004; Little, 2003; Neufeld \& Roper, 2002; Smylie \& Perry, 2005) As teaching is an isolated profession and autonomy is highly regarded. Many teachers are reluctant to allow their colleagues to get into their classrooms for fear that they will be evaluated or judged (Johnson \& Donaldson, 2007). It is also true in the case of most college English teachers in China's higher education according to lots of the academic research papers concerning teachers' professional development published in recent years. In 2012, two university English teachers and I made a survey on college English teacher professional collaboration in three universities in Shan dong province. Shan dong province is an economically middle-level province in China, and the three universities we choose are respectively one nationally key university, one provincially key university and a common one. So the sample is of the representative significance. Among the 260 interviewees, about $90 \%$ of them show reluctance to allow other teachers to observe their teaching; $85 \%$ dislike to show the way of their teaching to their colleagues even though the teaching effect is good in their classroom, saying that it is quite another thing to get up in front of your coworkers and tell them they should teach 
differently, which is especially true for some young teachers who think that they are not qualified to introduce their experience to the veterans; $80 \%$ are unwilling to share academic research with their colleagues because of peer competition in promotion. In the culture of isolation and competition, most interviewed teachers show they feel lonely and helpless in professional development.

What role the administrators of the university department play in supporting college English teachers' professional development? According to the survey, the professional development supporting activities of the administrators include giving teachers chance to attend academic conference or receive professional training during summer vacation, inviting experts to give lectures, holding academic saloon within the university department, veteran teachers coaching the fresh ones, encouraging teachers to be visiting scholars inland or abroad.

How about the effects of these professional development supporting activities? The following chart is the voting results of the interviewed teachers:
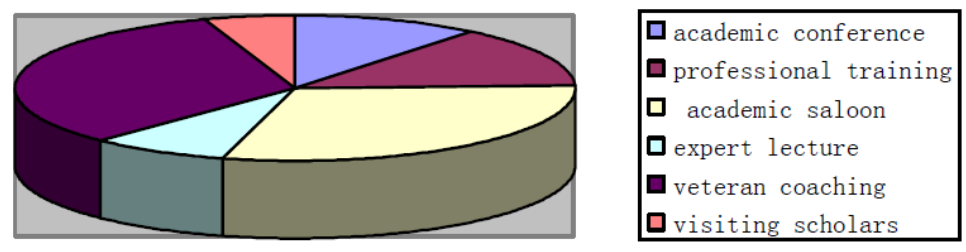

From the chart it can be seen the percentages of teachers choosing academic conferences, professional training sessions and being visiting scholars are respectively below $40 \%$, more than $50 \%$ of the teachers choose academic saloon within the university department and veteran teachers coaching as more effective ways to get professional development. From further interviews we get to know most teachers admit the summer vacation conferences held by publishing companies in a large part are taken as the teachers' tour experience instead of a serious academic activity; as for professional training sessions, some teachers say they are usually unrelated to teachers' work; only $10 \%$ choose being visiting scholars, because at present most teachers cannot get the chance. The reason that more than $50 \%$ of the teachers choose academic saloon within the university department and veteran teachers coaching is that they are most approachable and related to their daily work.

In a conclusion, collaborative professional development mode is preferred by most college English teachers, as it is based on constructivism rather than the top-down training-oriented model. Teachers hope to be regarded as active learners, learning from each other collaboratively by engaging the concrete task of teaching, assessment, observing colleague teaching and reflecting their own teaching practice in the professional community.

\section{B. The Approaches to Introducing PLA into College English Teachers' Professional Development}

\section{Organizational Restructure}

Organizational structure decides how power is exercised and how administrators provide their support to promote teachers' professional development. Research has demonstrated that traditional, hierarchical school structures put barriers to shared leadership (Forster, 1997), as it involves the concept of one leader, which is considered synonymous with the boss and supervisor, coupled with the traditional patterns of dependency relationships. Shared leadership is inhibited by the hierarchical structures isolating teachers, and that reinforce core professional norms such as autonomy and privacy.

In most higher education of china, the traditional, hierarchical structure is still the popular organizational form, with the dean as the sole leader in university department who deals with all the managerial affairs and designs the activities related to teachers' professional development, while teachers as the passive receiver of all kinds of training. The rare chances of active participation and the culture of isolation and competition make most teachers lack the impetus in professional development. So in order to turn the traditional teachers' group into a professional learning community, the hierarchical organization structure must be transformed first.

First introduced in the mid 1900's, distributed leadership has emerged as a tool to effectively fight against the frustrations of the traditional, hierarchical structure. In distributed leadership, leadership is spread over an organization, rather than resting in the hands of a few at the top of an organizational hierarchy (Bennett, et al., 2003; Lambert, 1998; Ogawa \& Bossert, 1995; Pounder, Ogawa, \&Adams, 1995; Spillane, et al., 2001). It encourages every teacher connected with school to be responsible for the progress of students and to take on leadership positions in the fields of their competence. Teacher leadership is no longer seen as a function of age, position, or job title. In fact, it is a characteristic of a community rather than an individual and is a responsibility taken on with the agreement of the community (Neuman \& Simmons, 2000). Distributed leadership continuum reflects total decentralization of leadership authority, which results in a flatter organization structure and a more powered, effective organization, "where teachers can continually expand their capacity to create the results they truly desire, where new and expansive patterns of thinking are nurtured, where collective aspiration is set free, and where people are continually learning to see the whole together" (Senge, 1990). In the case of China's higher education, the dean of the department should distribute leadership 
by encouraging teachers with different specialties such as classroom teaching, linguistic study, literature study, cross-culture study, educational theory research to take on leadership duties in organizing different academic groups. In this way, teachers are provided with more opportunities to exercise their strengths within their organization. Besides the formal positions in different academic groups, teachers' informal leadership should also be encouraged, through which more teachers can involve themselves into sharing their successful experience or skills with peers. For example, a teacher may be asked to share some recent research at a staff meeting, or lead a kiosk on a specific topic of interest, or share a useful teaching strategy with each other. In this way, most college English teachers can change the former passive professional development mode into the active and self-driven one. Teachers become the subject of their own professional development instead of the object of being changed.

2. The Change of Teachers' Mental Models

"Mental models" (Senge et al., 1994) determine the details each of us pays attention to and shapes our actions. The differences in mental models can be reflected in the innate levels of trust and how that shapes a person's behavior. For example, a person who believes others are basically trustworthy, may interact with new acquaintances more freely than those who don't trust other people.

In the case of college English teachers in China, because of long-time working in the isolating and competitive culture, most of them have the mental model of competition instead of the cooperation with others, they are not accustomed to the style of working together and team learning is a difficult way of being both intellectually and socially, which in fact, create barriers to teachers' professional development, as they waste the most valuable learning resource - their peers. So it is imperative for the administrators in the higher education of China to foster the culture of group development. Some measures must be taken, for example, dedicating professional time toward a collective understanding of group development and ways to intervene to foster group development; keeping the vision of collaborative practice as a genuine priority, rather than an add-on (Leonard \& Leonard, 2003; Garmston \& Wellman, 1999); changing the rewarding form from individual to collective etc..

3. Models of Teacher Professional Development Activities in a PLA

The characteristics of teacher development activities in a PLA reflect the developing trend of recent educational research in teachers' professional development which is changing from 'sit-and-get' workshops on general topics to teacher-driven efforts to identify and find solutions to teaching problems related to their teaching practice. The three examples below which focus on new teachers' professional development, doing academic research and learning cooperation show us some possible approaches to the problem respectively.

Mentoring New Teachers: guiding new teachers gives both the new and master teachers chances to learn from each other. It is especially effective on helping the new one learn how to cope with the daily teaching challenges. Supervising happens around practices like observing peer class, assisting preparing lessons, teaching feedback, and cooperative teaching. It directly influenced the teaching attitude, teachers' efficacy and expansion of their teaching strategies. (Smith, 2002).

Learning Collaboration: "Teacher learning is most likely when teachers collaborate with professional peers, both within and outside of their schools, and when they gain further expertise through access to external researchers and program developers" (King \& Newmann, 2000, p. 576). Teachers' learning cooperation can encourage continual inquiry and reflection through active learning. It is a very significant form of professional development to teachers because they can wield the ownership of its content and process by engaging in peer discussions, cooperative planning and learning as parts of their professional development activities. For example, teachers can have a content-based collaborative inquiry about a new teaching method by posing questions about data collection and analysis, its effects on the learners' reflection. Then they can share the results with peers, and collaboratively create corresponding solutions. During this process, teachers deepen their knowledge of subject and educational theories which supplement student learning accordingly (Bray, Gause-Vega, Goldman, Secules, \& Zech, 2000). Teachers can also develop teaching materials addressing students' learning requirements by creating models about how students think and solve problems. This process provides possibilities for teachers to have a better understandings of their teaching subject and they work out ways to teach it more successfully (Carpenter, Fennema, Franke, \& Levi, 2001).

Colleague Observation: observing peer's class practice is another model of utilizing colleague collaboration to support teachers' instructional advancement and professional development. It is a process of several steps in which teachers cooperatively prepare their lesson plan, learn together and advance their teaching skills. A member of the teaching community gives a lesson and the others observe in details. After class, teaching community members get together and have a discussion of their observation details and make efforts to provide strategies of further improving the lesson. After teaching the revised lesson again to a different class, the above steps such as detailed-observation, cooperatively analyzing data and revising lesson plan is made once again.

Collaborative Lesson Planning: the same teaching material and similarity in students' language levels make it possible for college English Teachers to cooperate with each other in lesson planning. Lesson planning can be a part of the staff meeting, in which teachers can talk about their lesson plans freely, exchange ideas about how to design a certain lesson, share adds-on teaching material and power points. In this way, teachers can not only save time in preparing lessons but also effectively enrich their lessons by adopting new strategies from their peers.

Academic Research Teams: teachers with different specialties such as classroom teaching, linguistic study, literature 
study, cross-culture study, educational theory research can be organized into different academic groups. In this way, teachers are provided with more opportunities to exercise their strengths within their organization.

\section{CONCLUSION}

Professional learning community is a new term to most college English teachers and administrators in China's higher education, though it has been taken by many western countries as an effective way to promote teacher professional development. It emphasizes the collaborative developing mode which offers teachers the opportunity to see themselves as part of a broader profession, where they are supported in broadening teachers' knowledge and skills and are encouraged to help each other in learning, which can reduce teachers' feeling of isolation in professional development due to the competitive culture. This paper only makes a brief introduction of the professional learning community and gives some suggestion of how to involve college English teachers' professional development into it. The author of this paper thus hopes this thesis would be valuable for further discussion in this area and more teachers and administrators would take efforts to put it into practice.

\section{REFERENCES}

[1] Barth, R.S., \& Foundation, R.I. (2001). Teacher leader. Phi Delta Kappa, 82(6), 443-449.

[2] Bennett, N., Wise, C., Woods, P., \& Harvey, J. A. (2003). Distributed leadership. National College for School Leadership.

[3] Bray, M. H., Gause-Vega, C. L., Goldman, S. R., Secules, T., \& Zech, L. K. (2000). Content-based collaborative inquiry: A professional development model for sustaining educational reform. Educational Psychologist. 35(3), 207-217.

[4] Carpenter, T. P., Fennema, E., Franke, M. L., \& Levi, L. (2001). Capturing teachers' generative change: A Follow-up study of professional development in mathematics. American Educational Research Journal. 38(3), 653-689.

[5] Camburn, E., Rowan, B.,\& Taylor, J.E.(2003). Distributed leadership in schools adopting comprehensive school reform models. Educational Evaluation and Policy Analysis, 25 (4), 347-373.

[6] Crowther, F., Kaagan, S., S., Ferguson, M., \& Hann, L. (2002). Developing teacher leaders :How teacher leadership enhances school success. Thousand Oaks, CA: Corwin Press.

[7] Forster, D., \& Durrant, J. (2003). Teacher leadership in a culture of change. School Leadership \& Management, 23(2), 173-186.

[8] Fullan, M. (1999).Change Forces: The Sequel. London: Falmer Press.

[9] Fullan,M. (2005). Leadership and sustainability: System thinkers in action. Thousand Oaks, CA: Corwin Press, Inc.

[10] Garmston, R., \& Wellman, B. (1999). The adaptive school: A sourcebook for developing collaborative groups. Norwood, MA: Christopher Gordon Publishers, Inc.

[11] Ganser T., (2000). “An ambitious vision of professional development for teachers”. In NASSA Bulletin, 84(618), 6-12.

[12] Guskey, T., (2000). Evaluating professional development. Thousand Oaks, CA: Corwin Press, Inc.

[13] Hiebert, J., Gallimore, R., \& Stigler, J. W. (2003). The new heroes of teaching. Education Week 23(10), 56, 42 http://www.edweek.org/ew/ew_printstory.cfm?slug=10hiebert.h23. Retrieved November 2003.

[14] Johnson, S. M., \& Donaldson, M. L. (2007). Overcoming the obstacles to leadership. Educational Leadership, 65(1), 8-13.

[15] Katzenmeryer, M., \& Moller, G. (2001). Awaking the sleeping giant: Helping teachers develop as leaders( $2^{\text {nd }}$ ed.). Thousand Oaks, CA: Corwin Press.

[16] King, M. B. \& Newmann, F. M. (2000) Will teacher learning advance school goals? Phi Delta Kappan. 81(8), 576-580.

[17] Lambert, L. (2003). Leadership capacity for lasting school improvement. Alexandria, Va.: Association for Supervision and Curriculum Development.

[18] Lambert,L.\&Association for Supervision and Curriculum Development. (1998). Building Leadership capacity in schools. Alexandria, Va.: Association for Supervision and Curriculum Development.

[19] Leonard, L. \& Leonard, P. (2003). Valuing schools as professional communities: Assessing the collaborative prescription. In Begley, P. \& Olaf, J. (Eds), The ethical dimensions of school leadership (pp. 127-142). Boston, MA: Kluwer Academic Publishers.

[20] Liberman, A., \& Miller, L. (2004). Teacher leadership. San Francisco: Jossey-Bass.

[21] Little, J. W. (2003). Inside teacher community: Representation of classroom practice. Teachers College Record, 105(6), 913-945.

[22] Louis, K.S., Marks, H.M., \& Kruse, S. (1996). Teachers' professional community in restructuring school. American Educational Research Journal, 33(4), 757-798.

[23] Mitchell, C. \& L. Sackney. (2000).Profound Improvement: Building Capacity for a Learning Community. Lisse, PA: Swets \& Zeitlinger.

[24] Neuman, M., \&Simmons, W. (2000). Leadership for student learning. Phi Delta Kappa, 82(1), 9-12.

[25] Neufeld, B., \& Roper, D. (2002). Off to a good start: Year 1 of collaborative coaching and learning in the Effective Practice Schools. Cambridge, MA: Education Matters, Inc. Retrieved October 8, 2004, from the ERIC database, ERIC Document Reproduction Service No.TM035260.

[26] Ogawa, R.T., \& Bossert, S. T. (1995). Leadership as an organizational quality. Educational Administration, Quarterly, 31(2), 224-243.

[27] Pounder,D. G., Ogawa, R. T. \&Adams, E.(1995). Leadership as an organization-wide phenomena: Its impact on school performance. Educational Administration, Quarterly, 31(4), 564-588.

[28] Senge, P. (1990). The fifth discipline: The art and practice of learning. New York: Doubleday.

[29] Senge,P., Kleiner,A., Roberts,C., Ross, R., \& Smith, B.(1994). The fifth discipline field book: Strategies and tools for building a learning organization. New York, NY: Bantam Doubleday Dell Publishing Group, Inc.

[30] Smith, S. (2002) Teacher mentoring and collaboration. Journal of Special Education Technology. 17(1), 47-48. 
[31] Smylie, M., \& Perry, G. (2005). Restructuring schools for improving teaching. In Fullan, M. (Ed.), Fundamental change: international handbook of educational change (pp. 308-340). The Netherlands: Springer Dordrecht, Publisher.

[32] Spillane, J. P., Harverson, R., \& Diamond, J. B. (2001). Investigating school leadership practice: A distributed perspective. Educational Researcher, 30(3), 23-28.

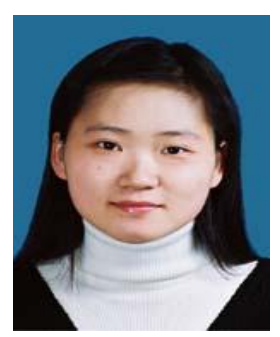

Ying Zhao, born on June 6, 1980, has got her master degree of arts specializing in English language \& literature from Shandong Normal University in 2005 and then been working in Shandong University of Finance and Economics as a lecturer of college English for years, is currently a PhD. Candidate majoring in educational theory at Shandong Normal University. 